\title{
"Antegrade flexible intramedullary nailing for fixation of displaced midshaft clavicle fractures"
}

\author{
Dr.Shishir.S.M ${ }^{1 *}$, Dr.Lingaraj ${ }^{2}$, Dr.Ashish Philip Zachariah ${ }^{3}$, \\ Dr. R.Kanagasabai ${ }^{4}$, Dr. Syed Najimudeen ${ }^{5}$, Dr James J Gananadoss ${ }^{6}$. \\ ${ }^{1 *}$ Assistant Professor, M.S.,D.N.B.,M.Ch.(ortho), Department of Orthopaedics, Pondicherry Institute of \\ Medical Sciences, Kalapet, Pondicherry-605014,India. \\ 2- Assistant Professor, D.N.B.,Department of Orthopaedics, Pondicherry Institute of Medical Sciences, Kalapet, \\ Pondicherry-605014,India \\ ${ }^{3-}$ Post-graduate,Department of Orthopaedics, Pondicherry Institute of Medical Sciences, Kalapet, Pondicherry- \\ 605014,India. \\ ${ }^{4-}$ Professor, M.S.,Department of Orthopaedics, Pondicherry Institute of Medical Sciences, Kalapet, \\ Pondicherry-605014, India. \\ ${ }^{5-}$ HOD and Professor, M.S.,Department of Orthopaedics, Pondicherry Institute of Medical Sciences, Kalapet, \\ Pondicherry-605014,India. \\ ${ }^{6-}$ Professor, M.S.,Department of Orthopaedics, Pondicherry Institute of Medical Sciences, Kalapet, \\ Pondicherry-605014,India.
}

\begin{abstract}
:
Introduction: Fractures of the clavicle are common injuries with an incidence of 5-10\% of all fractures[1]. These fractures are generally managed conservatively. Titanium elastic nails are a promising minimally invasive treatment for displaced mid-clavicular fractures, which may be an alternative to plate fixation or even nonoperative treatment. The aim of the present study was to evaluate the functional and radiological results of intramedullary fixation of mid-clavicular fractures.

Methods: Between January 2007 and June 2013, 48 patients with type A and type B middle third clavicle fractures (OTA Classification) underwent flexible intramedullary nailing with titanium elastic nail. Implant removal was performed in all the patients after the fracture united completely.

Results: The mean constant shoulder score for 47 patients at 6 weeks was 56.98 (range: 44-72), at 3 months was 91.25 (range: 54-98), at 6 months was 96.38 (range:64-100), at 12 months was 98.75 (range:68-100), at 18 months was 99.50 (range:78-100), and at the end of 24 months it was 99.58 (range:80-100).

Conclusion: Flexible intramedullary nailing, a minimally invasive technique for stabilization of displaced midshaft clavicle fractures is a simple procedure with excellent functional outcome in terms of quick return to sporting activities and a high patient satisfaction rate.
\end{abstract}

Keywords: Clavicle plating, Intramedullary clavicle nailing, middle $1 / 3$ rd clavicle fractures, Titanium elastic nailing System (TENS).

\section{Introduction}

"Midclavicular fractures heal without the doctor, with the doctor, and despite the doctor!"[1]. Fractures of the clavicle are common injuries with an incidence of 5-10\% of all fractures [1,2,3]. Most commonly, these fractures occur within the middle third of the clavicle and exhibit some degree of displacement. Many midshaft clavicle fractures can be treated non-surgically. Recent evidence suggests that more severe fracture types exhibit higher rates of symptomatic non-union or malunion[4]. Although the indications for surgical fixation of midshaft clavicle fractures remain controversial, they appear to be broadening. Eighty percent of all fractures involve the middle third of the clavicle[4,5] . The most probable cause of injury is an indirect trauma such as a fall on the shoulder or on the extended $\mathrm{arm}^{5}$. Midclavicular fractures are generally managed conservatively, e.g. with a figure-of-eight-bandage. Imminent perforation of the skin, impending or existing neurovascular compromise and the floating shoulder represent absolute indications for operative treatment. Gross displacement of fracture fragments, as well as non-unions, are seen as relative indications for surgical fixation.

Various methods of fixation have been described in literature, of which plating and intramedullary nailing are the most popular ones. Intramedullary nailing of clavicle middle $1 / 3^{\text {rd }}$ fractures using the titanium elastic nail has been described as a technically easy, minimally invasive operation with few complications and an early return to work[6,7]. The complication rate has been reported to be low[6-8]. Plate osteosynthesis is the gold standard for operative treatment, but higher complication rates have been observed with this technique in comparison to conservative management $[9,10]$. 
The aim of the present study was to evaluate the functional and radiological results of intramedullary fixation of mid-clavicular fractures.

\section{Material and methods}

We analysed the outcome of a consecutive series of 48 patients with mid-clavicular fractures that were treated with titanium elastic nails between January 2007 and June 2013 in Department of Orthopaedics, Pondicherry Institute of Medical sciences, Pondicherry.

Clavicle middle third fractures were classified as A-type fractures (simple fractures, two fragments), Btype fractures (fractures with bending wedge) and C-type fracture (complex fractures) according to the classification of the Orthopaedic Trauma Association (figure 1). Thirty four patients (70.8\%) had an A-type fracture with a cranial displacement of the medial fragment due to the pull of the sternocleidomastoid muscle. B-type fractures $(29.2 \%)$ were observed in 14 cases. Type $\mathrm{C}$ fractures were not considered for nailing as they were plated in most of the cases.

Absolute indications for surgery were present in 23 patients. These were (imminent) skin perforation or tenting $(\mathrm{n}=20)$ and multiple ipsilateral rib fractures with respiratory insufficiency $(\mathrm{n}=3)$. Patients with floating shoulder, bony injuries of ipsilateral upper limb, brachial plexus injury and bilateral clavicle fractures were not considered for the study as it would affect the outcome. Rest of the 25 patients were treated surgically because of major displacement of the fracture. The average displacement was $150 \%$ of diaphyseal width and the clavicular shortening ranged from 1 to $3.2 \mathrm{~cm}$. All patients with relative indications for surgical fixation were young; they did not want a brace and wanted to return to their pre-injury status as soon as possible.

The intra-operative complication observed consistently was the difficulty in manoeuvring the nail at the lateral end of the clavicle as it curves posteriorly and flattens out laterally. Opening the fracture site with a two centimetre incision and use of a towel clip/reduction forceps aided in smooth passage of nail laterally.

\section{Operative technique -}

The surgical procedure was done under general anaesthesia. Patient was placed in the supine position with a sand bag in the inter-scapular region. We have also used semi-beach chair position in some cases as it gives a head on position of the clavicle. At the sternal end of the clavicle, a skin incision of $1 \mathrm{~cm}$ was made parallel to the clavicle. The anterior cortex was opened with an awl about $1.5 \mathrm{~cm}$ lateral to the sterno-clavicular joint (figure 2). A TENS (average diameter $2.0 \mathrm{~mm}$ ) which was mounted over a T-handle was inserted and advanced to the fracture site (figure 3). Subsequently; the fracture was reduced in a closed manner. If closed reduction was not possible, a $2 \mathrm{~cm}$ skin incision at the level of the fracture site was made for mini-open fracture reduction. Reduction was maintained provisionally with a small reduction forceps or towel clip. The nail was subsequently advanced across the fracture into the lateral fragment with gentle rotational movements (figure 4). Care was taken not to advance the nail too laterally in order to avoid penetration into the acromioclavicular joint. Fluoroscopic control is therefore mandatory. The nail was then bent and cut with a blunt tip and buried under the skin. Skin was then closed with sutures.

After surgery, the patient was put on an arm sling. All patients were started on passive shoulder mobilization exercises on the $2^{\text {nd }}$ post-operative day. Check x-ray was done 3 weeks post surgery to assess for alignment (figure 6). Active mobilisation was started 3 weeks after surgery. Arm sling was discontinued after 6 weeks (figure 7).

\section{Results}

The average age was 36.65 years (SD: 19 to 58 years). Out of the 48 patients, 33 were male $(68.8 \%)$ and 15 were female $(31.3 \%)$. Thirty one patients sustained injury to right clavicle $(64.6 \%)$ compared to 17 who sustained injury to the left clavicle $(35.4 \%)$. Most injuries resulted from road traffic accidents $(n=32)$, followed by fall from a height $(n=9)$, and direct blow $(n=7)$.

The mean duration of surgery was 70.79 minutes (range: 45-100 min). An open fracture reduction via an additional small incision was necessary in 40 patients and closed manoeuvre was successful in 8 patients. Out of the 48 patients, fracture in 47 patients went on to unite over an average period of 10.4 weeks (ranging from 8 weeks to 16 weeks). There were no neurovascular complications. One infected non-union with implant failure was noted with gross bending of the nail at the fracture site. Implant removal was done and fracture resulted in a non-union (figure 10). Patient did not want any further procedure and was lost to follow-up. (Table 1).

The mean constant shoulder score (table 2) at 6 weeks was 56.98 (range:44-72), at 3 months was 91.25 (range: 54-98), at 6 months was 96.38 (range:64-100), at 12 months was 98.75 (range:68-100), at 18 months was 99.50 (range:78-100), and at the end of 24 months it was 99.58 (range:80-100). In 2 cases there were malunion with superior angulation of 22 degrees and 15 degrees as assessed by radiographs (figure 8). Two patients had superficial wound infection at 2 weeks and 6 weeks post-op respectively requiring wound wash. Staphylococcus aureus and MRSA was grown on culture, respectively. Infection subsided with intra-venous antibiotics and 
regular dressings. Fracture subsequently united. Three cases in the type B group had delayed union which needed additional bone grafting procedure at a later stage (figure 9 ).

Table 1: showing the descriptive statistics of various data analysed

\begin{tabular}{|l|l|l|l|l|l|}
\hline \multicolumn{6}{|c|}{ Table 1: showing the descriptive statistics of various data analysed } \\
\hline & $\mathrm{N}$ & Minimum & Maximum & Mean & Std. Deviation \\
\hline Age & 48 & 19 & 58 & 36.65 & 11.165 \\
Duration of surgery & 48 & 45 & 100 & 70.79 & 13.679 \\
TIME OF UNION & 47 & 8 & 16 & 10.40 & 1.907 \\
6 weeks & 48 & 44 & 72 & 56.98 & 6.107 \\
3 months & 48 & 54 & 98 & 91.25 & 7.070 \\
6 months & 48 & 64 & 100 & 96.38 & 5.421 \\
12 months & 48 & 68 & 100 & 98.75 & 4.624 \\
18 months & 48 & 78 & 100 & 99.50 & 3.182 \\
24 months & 48 & 80 & 100 & 99.58 & 2.887 \\
Valid N (listwise) & 47 & & & & \\
\hline
\end{tabular}

Table 2: showing the mean constant score at various intervals of follow-up

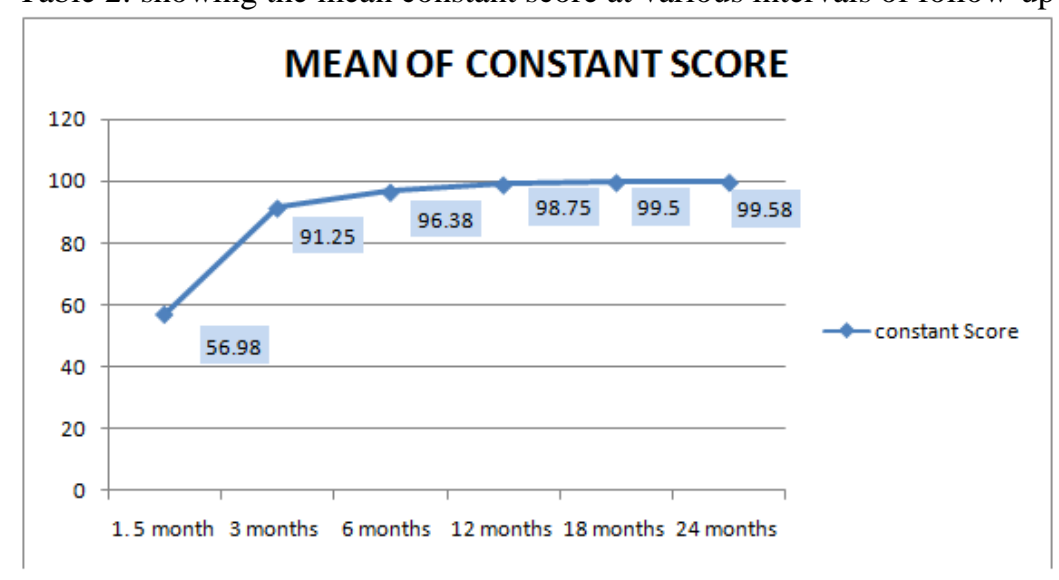

Nail prominence was felt by 34 patients at the sternal end, but was not of much concern to the patient. Two patients required revision of the cut end of the nail under local anaesthesia. All patients had returned to their previous activity level at approximately four months follow-up with full range-of-motion and strength in the affected extremity.

The mean duration of implant removal was 5 months and 2 weeks (range-4-7 months) post surgery following the union of fracture. Implant removal was done under general anaesthesia in operation theatre in all patients.

\section{Discussion}

Mid-clavicular fractures in our country are being treated conservatively until date. Rowe[4] and Neer[2] in the 1960's recommended non-operative treatment, because they observed a very small number of non-unions. Conservative treatment subsequently became the standard procedure for the management of nondisplaced and displaced mid-clavicular fractures as well. The treatment of displaced mid-shaft clavicle fractures has evolved over the past several years based on recent clinical studies demonstrating high rates non-union and symptomatic malunion with non-operative treatment[9-16]. Also, more recent studies had observed satisfactory functional and radiological outcome after non-operative treatment. The indications for operative treatment were limited to skin perforation or tenting, gross displacement and associated neurovascular complications[17].

Proponents of intramedullary fixation of clavicle fractures believe that this method of fixation avoids periostium stripping and can be achieved through a smaller and more cosmetically acceptable scar than plating[18]. However, in a retrospective review of cases, Grassi et al.[7] found that adverse events such as infection, re-fracture, and non-union occurred in 35\% of patients undergoing intramedullary fixation; a significantly higher complication rate than non-operative treatment. Their method, however, involved a transverse incision much like the incision used for plating today, and they removed the pin within 60 days[7].

Ngarmukos et al.[18] described double K-wire fixation through a longitudinal incision and removed metal work between 6 months and 1 year post fixation and 1 infection requiring implant removal and no nonunions in a cohort of 86 patients. Their wires, however, did not have a locking mechanism; and in three patients, metal work had to be removed because of migration[18]. 
Jubel et al.[8] have described elastic nailing of the clavicle from medial to lateral, with the lateral end of the clavicle closed to prevent migration in 55 patients. They described 1 non-union, requiring plating and 3 patients having their metalwork trimmed due to soft tissue irritation[8]. This may be because of a medial entry point, where there is little soft tissue cover. Ring and Holovacs[19] described 3 cases of transient brachial plexus palsy after insertion of Rockwood Pin. The authors admitted that 2 of the cases were delayed unions that required excessive force to deliver the fragments into the wound. All cases resolved spontaneously with improvement seen after the second post-operative week[19].

The results regarding the outcome of conservative treatment of displaced mid-clavicular fractures nowadays, however, are seen in a more differentiated manner and they are controversially discussed. Wick et al.[13] and Eskola et al.[20] observed high rates of non-union, shoulder pain and poor functional results when the fracture had healed with shortening of more than $2 \mathrm{~cm}[13,21]$. These findings were confirmed by Lazarides et al.[22] and by Hill[23]. These studies favour operative treatment of displaced mid-clavicular fractures by describing high rates of good and excellent results. Although plate fixation provides adequate stability, Rowe $e t$ al.[4] and Bronz et al.[24] described complications like non-union, re-fracture or loosening of implants. Similar complications have been described with intramedullary pinning[21] . Minimally invasive elastic titanium nailing was established as an alternative to plate fixation[25,26]. Jubel et al.[8] showed that the correction of clavicular shortening is a pre-requisite of good functional outcome. They did not observe non-union or poor post-operative outcome.

In this study, intramedullary nailing provided early functional recovery. Patients today have high expectations of the functional outcome. They expect rapid and pain-free functional recovery following a fracture. In contrast to conservative treatment, minimally invasive techniques can fulfil these objectives with a reduced risk of complications[6]. TENS however has its own complication rate: the sternal ends of the TEN can cause skin irritation and pain. Most of the patients complained about the nail prominence at the sternal end but tolerated it well till removal.

In summary, we believe that operative management of mid-shaft clavicle fractures with flexible intramedullary nailing is a safe procedure with excellent clinical and functional outcomes.

\section{Conclusion:}

The acute treatment of middle-third clavicle fractures remains a subject of controversy. In comparison with plate fixation, TENS is less invasive and requires smaller incisions. In comminuted fractures that are at risk of telescoping, plate fixation however remains the procedure of choice.

The data demonstrates early pain relief in combination with good shoulder function after acute operative treatment resulting in quick return to sports activities and a high patient satisfaction rate. Titanium elastic nails are a promising minimally invasive treatment for displaced mid-clavicular fractures, which may be an alternative to plate fixation (ORIF) or even non-operative treatment.

\section{Acknowledgement}

We sincerely thank MR. RAVICHANDRAN, Lecturer, Department of biostatistics, Pondicherry Institute of Medical Sciences for having analysed the data statistically.

Consent: All patients have given their informed consent for the publication of this case series.

"The author(s) declare that they have no competing interests".

\section{No funding received from any source for the study.}

Ethical clearance from the ethical committee has been obtained for the above study.

\section{References:}

[1]. GereonSchiffer, ChristophFaymonville, Emmanouil Skouras, Jonas Andermahr, Axel Jubel .MidclavicularFracture:Not Just a Trivial Injury. Current Treatment Options.DeutschesÄrzteblatt International | DtschArzteblInt 2010; 107(41): 711-7.

[2]. Neer C. S. (1984) Fractures of the clavicle. In : Rockwood C. A., Green D. P. (eds.). Fractures in Adults. 2nd ed. Philadelphia : JB Lippincott 707-713.

[3]. Nordqvist.A.,Petersson.C. The incidence of fractures of the clavicle.ClinOrthop, 1994, 300: 127-132.

[4]. Rowe C. R. An atlas of anatomy and treatment of mid-clavicular fractures.ClinOrthop, 1968, 58: 29-42.

[5]. Allman F. L. Fractures and ligamentous injuries of the clavicle and its articulation. J Bone Joint Surg, 1967, 49-A: 774-784

[6]. Kettler M, Schieker M, Braunstein V, K“onig M, Mutschler W. Flexible intramedullary nailing for stabilization of displaced midshaft clavicle fractures: technique and results in 87 patients. ActaOrthop. 2007;78:424-9.

[7]. Grassi F. A., Tajana M. S., D’Anjelo F. Management of midclavicular fractures : a comparison between non-operative treatment and open intramedullary fixation in 80 patients. J Trauma, 2001, 50: 1096-1100.

[8]. Jubel A, Andermahr J, Schiffer G, Tsironis K, Rehm KE. Elastic stable intramedullary nailing of midclavicular fractures with a titanium nail. ClinOrthopRelat Res 003;408: 279-85.

[9]. Bostman O., Manninen M., PIihlajamak H. Complications of plate fixation in fresh, displaced midclavicular fractures. J Trauma, $1997,43: 778-783$.

[10]. Constant C. R. A clinical method of functional assessment of the shoulder.ClinOrthop, 1987, $214: 160-164$.

[11]. Canadian Orthopedic Trauma Society. Nonoperative treatment compared with plate fixation of displaced midshaft clavicle fractures. A multicenter, randomized clinical trial. J Bone Joint Surg Am. 2007; 89: 1-10. 
[12]. McKee MD, Wild, LM, Schemitsch EH. Midshaftmalunions of the clavicle.Surgical Technique.J Bone Joint Surg Am. 2004 ; 86 Suppl 1: 37-43.

[13]. Wick M, Muller EJ, Kollig E, Muhr G. Midshaft fractures of the clavicle with a shortening of more than $2 \mathrm{~cm}$ predispose to nonunion. Arch Orthop Trauma Surg. 2001; 121: 207-11.

[14]. McKee MD, Pedersen EM, Jones C, Stephen DJ, Kreder HJ, Schemitsch EH, Wild LM, Potter J. Deficits following nonoperative treatment of displaced midshaft clavicle fractures . J Bone Joint Surg Am. 2006; 88: 35-40.

[15]. Robinson CM, Court-Brown CM, McQueen MM, Wakefield AE. Estimating the risk of nonunion following nonoperative treatment of a clavicular fracture.J Bone Joint Surg Am. 2004; 86: 1359-65.

[16]. Kashif Khan LA, Bradnock TJ, Scott C, Robinson CM. Fractures of the clavicle. Current concepts review. J Bone Joint Surg Am. 2009; 91: 447-460.

[17]. Chen CE, Liu HC. Delayed brachial plexus neuropraxia complicating malunion of the clavicle.Am J Orthop.2000; 29 : 321-2.

[18]. Ngarmukos C, Parkpian V, Patradul A. Fixation of fractures of the midshaft of the clavicle with Kirschner wires. Results in 108 patients. J Bone Joint Surg [Br] 998;80: 106-8.

[19]. Ring D, Holovacs T. Brachial plexus palsy after intramedullary fixation of a clavicular fracture. A report of three cases. J Bone Joint Surg Am 2005;87: 1834-7.

[20]. Eskola A., Vainionpaa S., Myllynen P., Patiala H., RokkanenP.The outcome of clavicular fracture in 89 patients. Arch OrthopTraumaSurg, 1986, 105: 337- 338.

[21]. Smekal V, Deml C, Irenberger A, Niederwanger C, Lutz M, Blauth M et al. Length determination in midshaft clavicle fractures: validation of measurement. J Orthop Trauma 2008;22:458-62.

[22]. Lazarides S., Zafiropoulos G. (2006) Conservative treatment of fractures at the middle third of the clavicle : The relevance of shortening and clinical outcome. J Shoulder Elbow Surg, 2006, 15(2) : 191-194.

[23]. Hill J. M., Mcguire M. H., Crosby L. A. Closed treatment of displaced middle third fractures of the clavicle gives poor results. J Bone Joint Surg Br, 1997, 79: 537-539.

[24]. Bronz G., Heim D., Pusterla C., Heim U. Osteosynthesis of the clavicle. Unfallheilkunde, 1981, 84: 319-325.

[25]. Meier C, Grueninger P, Platz A. Elastic stable intramedullary nailing for midclavicularfractures in athletes: indications, technical pitfalls and early results. ActaOrthop Belg. 2006;72:269-75.

[26]. Mueller M, Burger C, Florczyk A, Striepens N, Rangger C. Elastic stable intramedullarynailing of midclavicular fractures in adults: 32 patients followed for 1-5years. ActaOrthop.2007;78:421-3.

\section{Figures:}

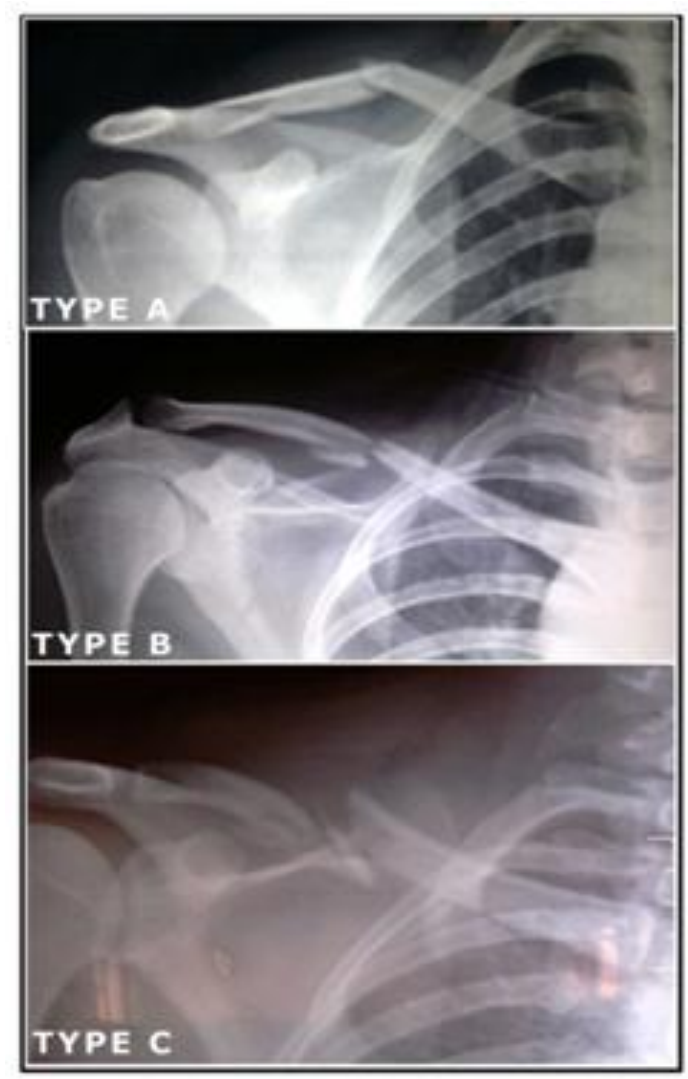

Figure 1: Orthopaedic Trauma Association (OTA) classification of middle third clavicle fractures. A-type fractures (simple fractures, two fragments), B-type fractures (fractures with bending wedge) and C-type fracture (complex fractures). . 


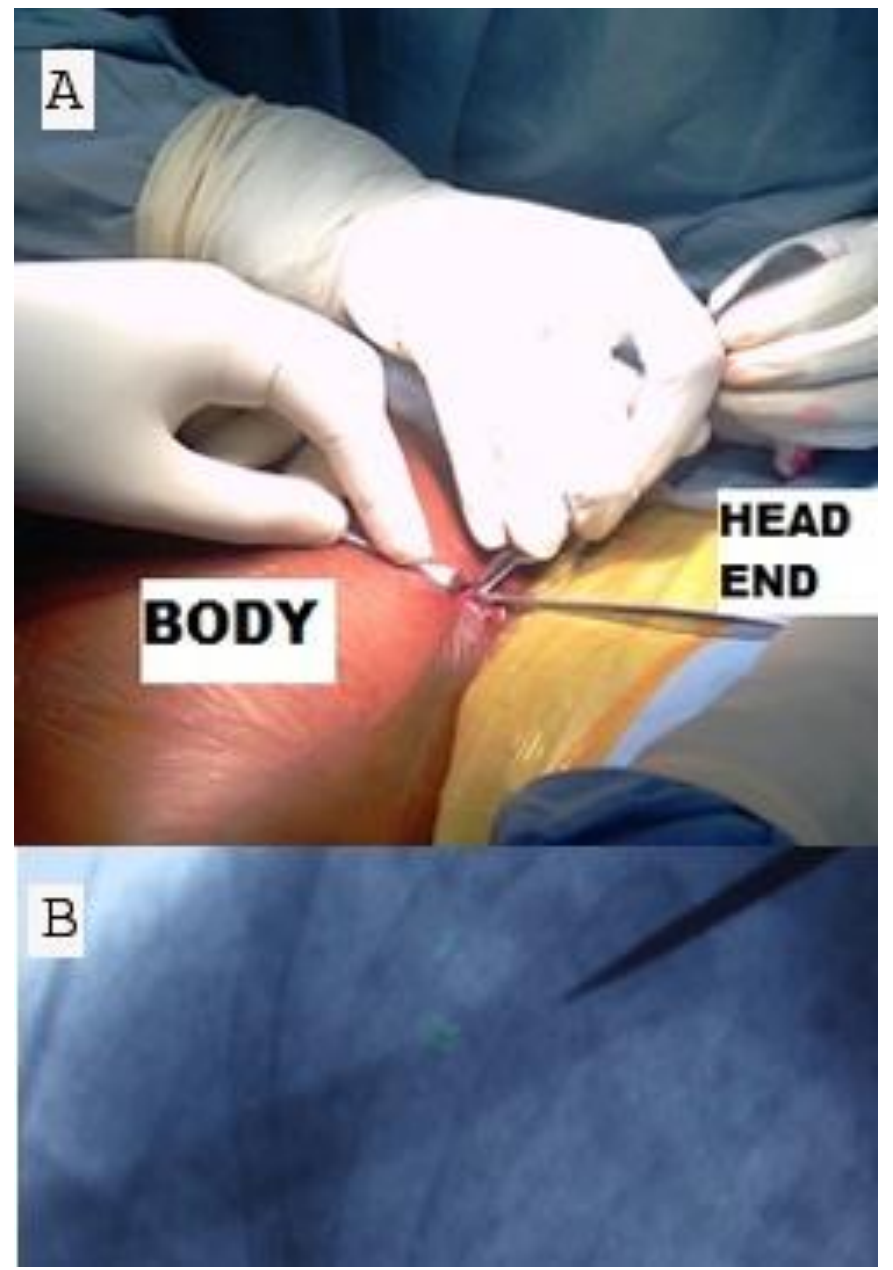

Figure 2:A. A small skin incision of $1-2 \mathrm{~cm}$ is made parallel to the clavicle about $1.5 \mathrm{~cm}$ lateral to the sternoclavicular joint. Entry at the sternal end of the clavicle made with an awl. B. Intra-operative fluoroscopy image showing the entry at the sternal end with an bone awl.

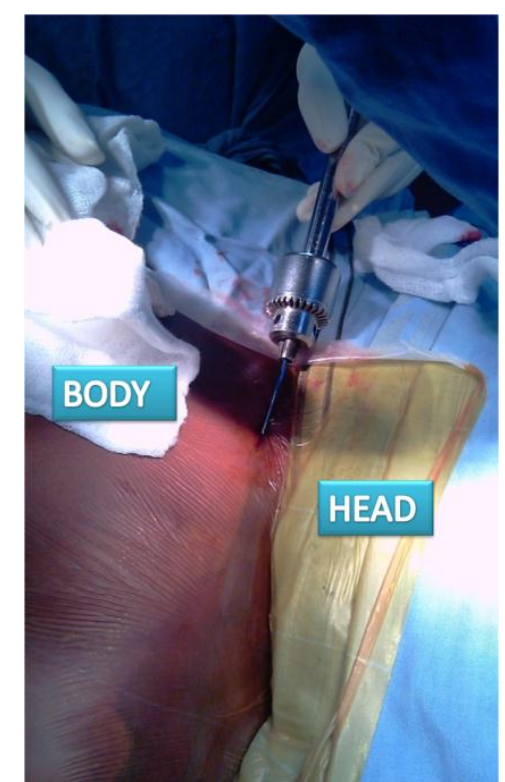

Figure 3: A TENS (average diameter $2.0 \mathrm{~mm}$ ) is inserted and advanced to the fracture site with the help of a Thandle. 


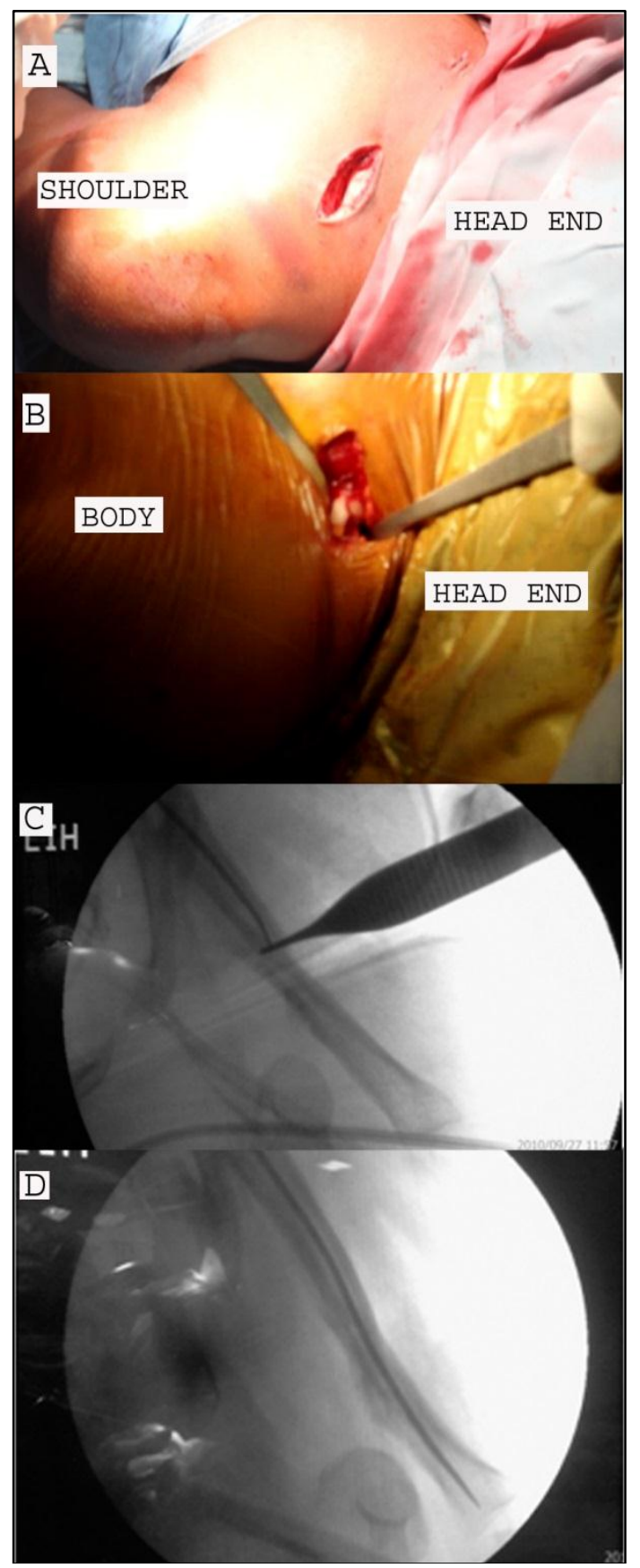

Figure 4:A. showing the fracture site being opened by a $2 \mathrm{~cm}$ incision. B. Intra-operative photograph showing fracture being reduced by bone levers. C. Intra-operative fluoroscopy image depicting the reduction. D. Intraoperative fluoroscopy image showing the fracture reduction with titanium elastic nail insitu. 


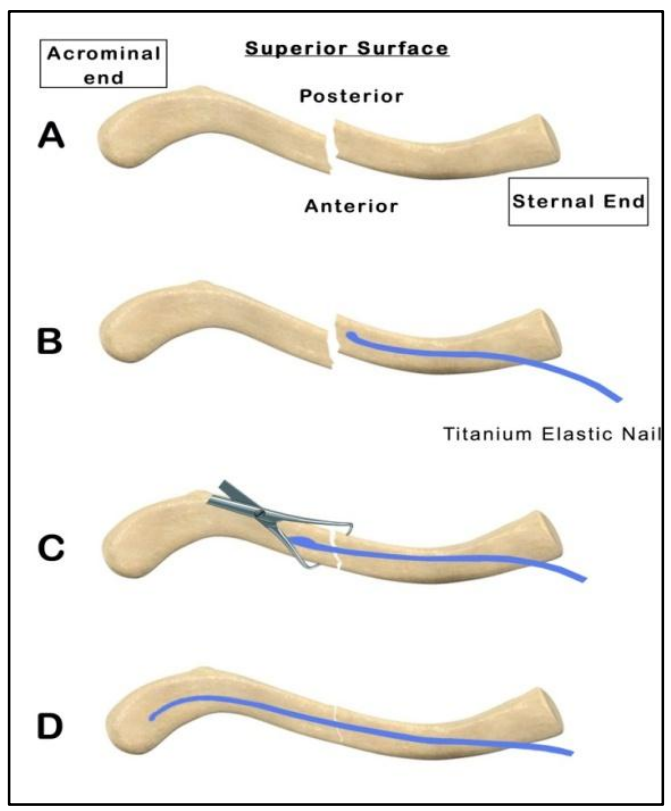

Figure 5: Pictorial representation of sequence of clavicle nailing. A. Clavicle middle third fracture. B. Titanium elastic nail being inserted from the sternal end of the clavicle. C. Fracture site being reduced by a pointed reduction forceps to facilitate the passage of the nail laterally. D. Fracture site reduced with titanium elastic nail insitu.

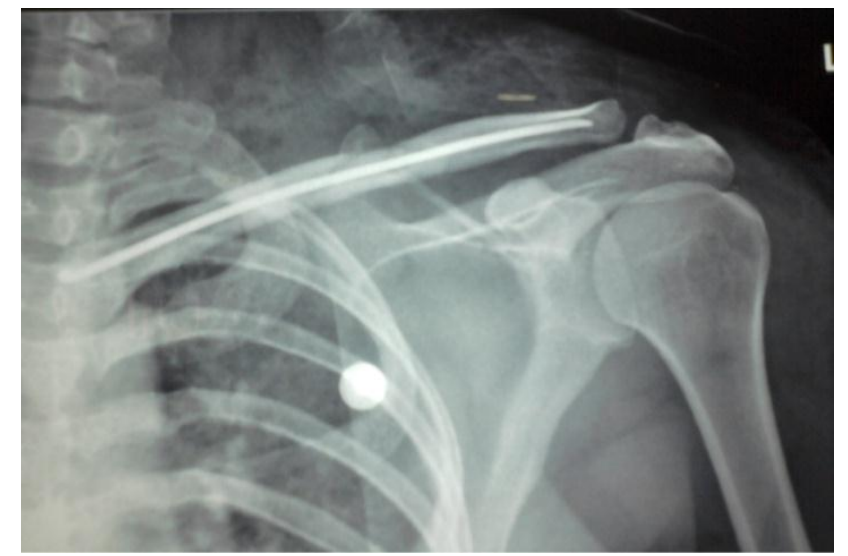

Figure 6: Post-operative x-ray showing good reduction and alignment of the fracture with Titanium elastic nail insitu.

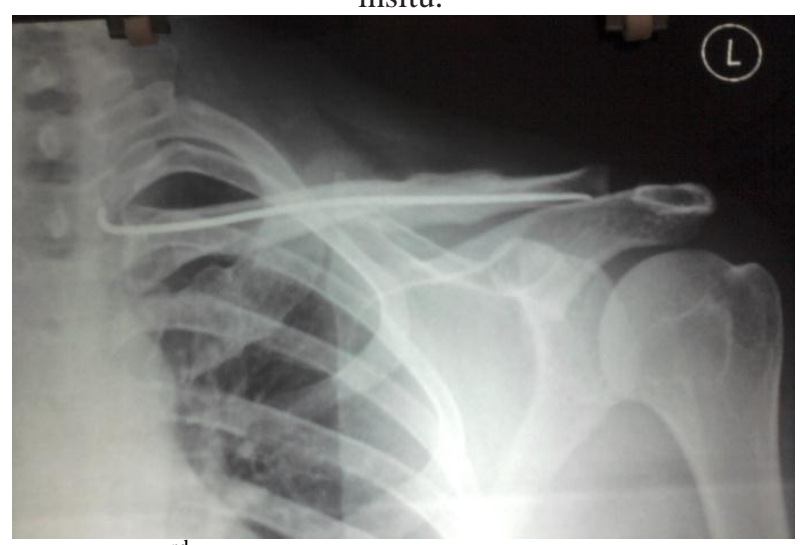

Figure 7: 12 weeks old left middle $1 / 3^{\text {rd }}$ clavicle fracture treated with Titanium elastic nail. Fracture has united well with good alignment and length of the clavicle is maintained as well. 


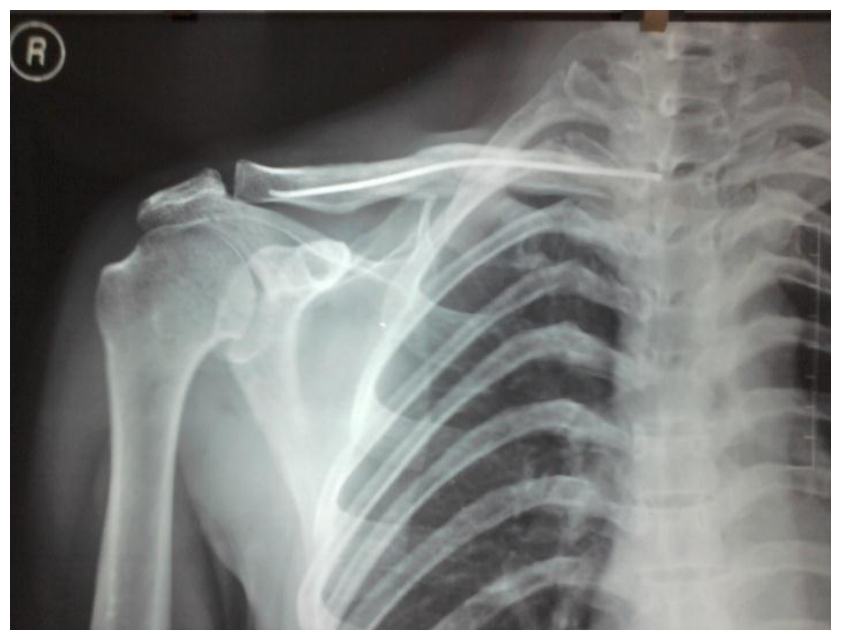

Figure 8: Malunion of clavicle due to hardware failure. The nail has bent at the fracture site resulting in superior angulation of 22 degrees.

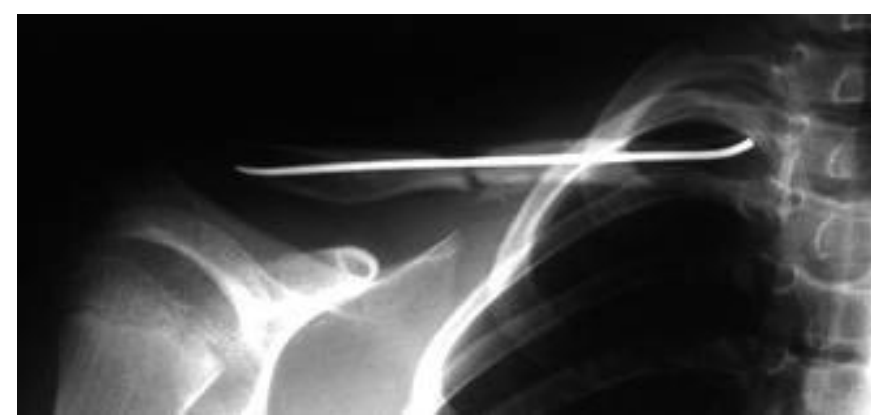

Figure 9: 10 weeks old mid-shaft clavicular fracture with flexible nail insitu . Gap is seen at the fracture site. Bone grafting was done. Fracture united after 2 months of grafting.

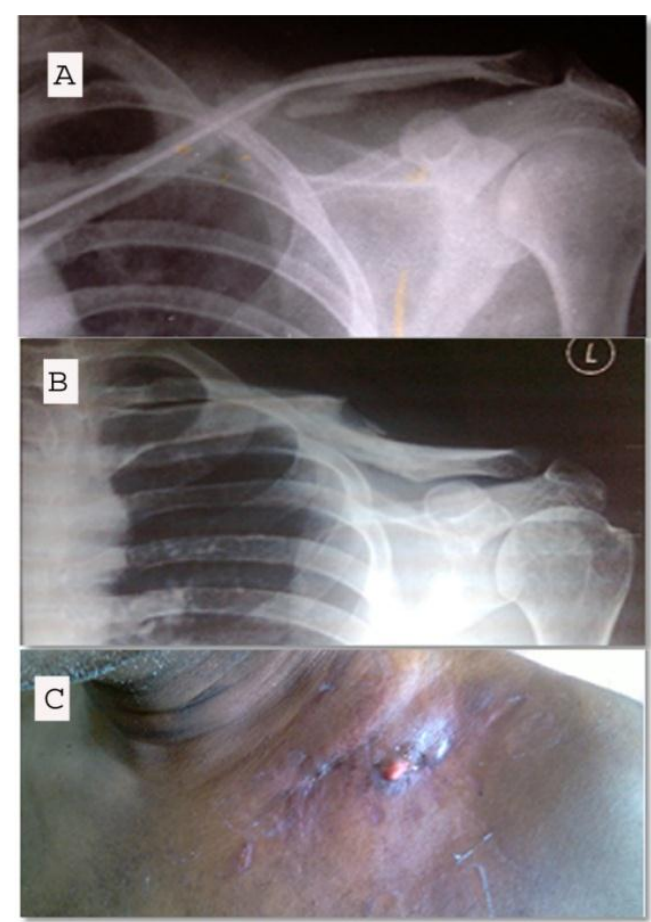

Figure 10: Case of infected non-union of left clavicle. A. Radiograph showing the nail angulation at the fracture site. B. Radiograph showing the non-union at the fracture site post nail removal and debridement. C. Clinical picture showing the pus discharge from the fracture site before implant removal and debridement. 